\title{
Split Air Conditioners and their role in Airborne Infection Spread.
}

\author{
Raja Singh ${ }^{1}$ \\ ${ }^{1}$ School of Planning and Architecture, Delhi
}

April 28, 2020

\begin{abstract}
As the World Health Organization denies COVID 19 being airborne in nature, there is some research done by the scientific community which differs in this approach. As prevention is always better than cure, it is always safe to give the benefit of doubt to prevention. Even as more data begins to be available regarding COVID, there is proven spread of airborne disease like tuberculosis being transmitted by this route. As the summer months approach, there will be increased use of Air Conditioners in the tropical regions of the world. India, too being in this part of the world sees an active rise in the indoors which are being air conditioned to meet the thermal comfort requirements of the rising urban population which is spending a large chunk of time indoors. This is coupled with the enforced lockdown which encourages people to stay indoors to prevent the spread of infection. In such situations the use of Split air conditioner requires rethinking as they re-circulate the indoor air without any Fresh air supply into the room. To reduce heat gain and save the electric load of the Split AC, people tend to seal the windows further. This requires some rethought by professionals.
\end{abstract}

Practical Implications of the paper: This letter to the editor brings forth the issue of use of Split Air conditioners which re-circulates air within a room. This contributes to the spread of airborne infection in the room. As the airborne nature of coronavirus is not clear, we have to still follow airborne prevention as later studies may prove a correlation as with SARS 2003. This awareness not only prevents disease, but also enables people achieve thermal comfort in the space responsibly. It also brings to light the bureaucratic ease of procuring individual split AC units over centralised systems.

Introduction

The World Health Organization has stated that the Coronavirus 2020 is not airborne in nature. There has been some contradictory speculations among the researchers in the world regarding this where it is stated that the chances of airborne transmission are plausible ${ }^{1}$. One major reason for this uncertainty may be the lack of data on the disease transmission dynamics as the priority right now is saving lives of the people. Even if this benefit of doubt is given to the World Health Organization, we must consider that there are proven airborne disease which exist in the world. Tuberculosis being one major infectious disease which propagates through the airborne route of transmission. This disease has a high rate of incidence amounting to 2.8 million new cases every year in India. Other disease like measles also spread through the airborne route.

In India, as the summer months approach, people will switch on the air conditioners. They will do this to cool the indoor spaces in order to provide adequate thermal comfort for themselves. There is a concern of the balance between providing adequate thermal comfort and the possible spread of air borne infections in the indoor spaces. This concern is particularly valid for the Healthcare facilities which have the highest risk of airborne nosocomial infection spread.

Buildings were earlier designed as solely naturally ventilated with complementary window openings, sun shade designs supporting wind movement and the presence of high ventilators along with provisions of 
ceiling fans. These buildings were simply retrofitted with split air conditioner units by simply sealing all the window openings and ventilators. Even though these buildings have provisions for opening/closing, they are seldom opened once the air conditioner has been installed.

If we start with educational institutes, the trend of air conditioning started from providing air conditioners in the computer laboratories in order to reduce the equipment heat up and thereby enabling efficient functioning of this computer equipment. Air conditioning leading to cooling of the air was once a luxury in the educational institutes. From the computer labs, the trend went to top management offices followed by conference seminar rooms and finally to faculty rooms. This has today been extended to student classrooms.

Split air conditioners have one major problem. In order to cool the indoor environment people are rapidly making the airtight. This is done to reduce the heat gain from outside which will increase the air-conditioning load and consequently the electric expenditure. The windows are being shut and the crevices on the edges of the doors and windows are being sealed. By doing so, there is no fresh air supply into the room and the same air within the room gets re-circulated. Split Air Conditioners have no mechanism for providing fresh air supply as the connection between the Indoor and the outdoor unit is just a simple exchange of the refrigerant and the condensate disposal pipe. There is no actual exchange of air using the pipe which connects the indoor and the outdoor unit. This situation prevents Air Changes per hour as prescribed by the National Building Code, $2016^{2}$. Research has shown that there is a direct correlation between the high rates of rebreathed air and disease occurrence ${ }^{3}$. Rebreathed air is the air inhaled by a person which has some percentage of the air exhaled by another person. This other person can be one suffering from a contagious airborne disease and his sneeze may be an aerosol suspended in the air. In such situations of recirculation of the same air, there is a high chance of people contracting an infectious airborne disease in case a person with the disease enters the room. This is all the more risky for the healthcare facilities where a Healthcare worker is exposed to a patient in a room where the air is recirculated due to the presence of a Split Air Conditioner which is commonplace in many clinics and hospitals (especially the ones which have been retrofitted by installing individual air conditioners.)

The current Central Public Works Guidelines (CPWD) accepts the split air conditioner unit as an acceptable method of air cooling to provide thermal comfort in individual rooms ${ }^{4}$. CPWD is the national policy body for construction in India apart from being the Project Management Consultant cum contractor for majority of the government projects in India. Due to the ease of tendering and ordering of individual air conditioner units vs. the cumbersome procuring of central AC units, the individual split air conditioners are being installed in government buildings across India. Sometimes due to administrative ease and to avoid the cumbersome tendering process, educational institutes chose to procure individual split air conditioner units for various rooms in institutional buildings. This includes installation of spit air conditioning units in large assembly spaces where students gather for culture performances or academic exercises. Here the rooms are sealed for retaining the cool are preventing hot air from entering. This is at the cost of Fresh Air supply to these large congregational spaces. This is further supported by the erstwhile DGS\&D (Directorate General of Supplies and Goods, Government of India) rate contract procuring system. This has been replaced by the current GEM (Government E Market Place, Government of India) procurement system which favors the purchase of individual Split Air conditioner systems due to easy purchase and no need for tendering.

For the healthcare facilities, this concern arising due to use of split air conditioners is all the more. There have been suggestions of the use of portable air purifiers in such healthcare facilities. The use of such portable air purifiers is all the more risky as according to the Indian Public Health Standards which states that these filters can pose a bigger threat as they can become the breeding grounds of infection spreads, if not maintained regularly ${ }^{5}$. The WHO guidelines on tuberculosis infection prevention and control, 2019 update suggests against the use of portable air filters as they are unable to provide the requisite number of air changes per hour ${ }^{6}$.

Another widely discussed method is the upper air ultraviolet germicidal irradiation use for killing the microbes in the space. This current paradigm of killing and sterilizing is being relooked by the researchers who are studying microbiomes in the indoor spaces. They suggest that there are bacteria present in the environment 
which are of benefit to human well-being. ${ }^{7}$ In this research, the number of bacteria were more with windows open, but their diversity was of less and more similar to Human disease causing bacteria which have their origin in the human skin and human spit. There are also some concerns with the ultraviolet radiations in habitable spaces and their effects on human health have not been fully studied. For low resource settings, this is not always the most cost effective method. Whereas dilution still remains as a cost effective solution for low resource setting. It enables the requisite numbers of air changes per hour required for 'flushing' of the contaminated air in these spaces. The new Guideline 'Severe Acute Respiratory Infection (SARI) Treatment Facility Design created jointly in March 2020 by WHO Architect Anna Silenzi and WHO Highly Infection Pathogens Expert Luca Fontana, suggests the use of dilution ventilation for the creation of makeshift treatment and screening centres for COVID-19. It is being distributed as an online course by the World Health Organization for Building Professsionals. ${ }^{8}$

There are some practical implications to doing away with the Split Air Conditioners. This includes the ease of installation and the cost with which the Split Air Conditioner becomes available to the consumer. Another concern is the entry of Pollution into the spaces due to the partial opening of the windows along with a running Split Air Conditioner. This problem can be taken care by the use of a Nano-Filters which prevents the entry of the particulate matter but will not let the air flow to and from the indoor space.

This area requires further attention of the Indoor Air Quality professionals and researchers in India and worldwide. This need for attention is further aggravated by our rising urbanization and the increasing time we are spending indoors.

\section{Funding and Conflict of Interest}

No funding was taken for this study. The author and the co-author declare to have no conflict of interest.

\section{References:}

1. Aerosol and Surface Stability of SARS-CoV-2 as Compared with SARS-CoV-1. Neeltje van Doremalen, et al. s.l. : The New England Journal of Medicine, 2020. 10.1056/NEJMc2004973.

2. SP(7) National Building Code. Standards, Bureau of Indian. New Delhi : Bureau of Indian Standard, 2016.

3. Shared Air: A Renewed Focus on Ventilation for the Prevention of Tuberculosis Transmission. Richardson ET, Morrow CD, Kalil DB, Bekker LG, Wood R. s.l. : PLOS ONE 9(5): e96334, 2014.https://doi.org/10.1371/jour

4. GENERAL SPECIFICATIONS forHEATING, VENTILATION \& AIR-CONDITIONING (HVAC)WORKS (2017). Central Public Works Department, Government of India. New Delhi : Central Public Works Department, Government of India, 2017.

5. Directorate General of Health Services, Ministry of Health and Family Welfare, Goverment of India. Indian Public Health Standards. New Delhi : Directorate General of Health Services, Ministry of Health and Family Welfare, Goverment of India., 2012.

6. Organization, World Health. WHO guidelines on tuberculosis infection prevention and control, 2019 update. Geneva: WHO, 2019.

7. Architectural design influences the diversity and structure of the built environment microbiome. Kembel, S., Jones, E., Kline, J. et al. 1469-1479 (2012), s.l. : ISME J 6.https://doi.org/10.1038/ismej.2011.211.

8. Anna Silenzi, Luca Fontana. Severe Acute Respiratory Infection (SARI) Treatment Facility Design. s.l. : World Health Oraganisation.https://openwho.org/courses/SARI-facilities. 